\title{
Genetic, morphological, and chemical patterns of plant hybridization
}

\author{
Alfredo López-Caamal ${ }^{1,2}$ and Efraín Tovar-Sánchez ${ }^{1 *}$
}

\begin{abstract}
Natural hybridization is a frequent phenomenon among vascular plants. Hybridization is considered an important evolutionary force since it may lead to (1) an increase of the intraspecific genetic diversity of the participating populations, (2) the creation of new species, (3) species extinction through genetic assimilation, and (4) the generation of highly invasive genotypes. Because of the importance of plant hybridization in evolution, it is of great importance to accurately identify hybrid individuals. In this review, we give a general historical background of the study of plant hybridization. Also, we review some of the tools employed for hybrid recognition and their pattern of expression in hybrid individuals (morphological, chemical, chromosome number, and DNA fingerprinting techniques). We emphasize that even when chromosome number, morphological characters, and chemical characters are of limited use for hybrid recognition in the absence of DNA fingerprinting techniques, their exploration may give insights of the ecological performance of hybrids. This is of special importance when hybridization leads to evolutionary novelty in the form of polyploidy, transgressive character expression, or the expression of new secondary metabolites not present in the parental species.
\end{abstract}

Keywords: Chromosome number; DNA fingerprinting; Hybrid performance; Hybrid phenotype; Invasive species; Secondary metabolites

\section{Introduction}

Natural hybridization is recognized as an important evolutionary process in plants, animals and fungi (Mallet 2005; Schwenk et al. 2008; Paun et al. 2009; Whitney et al. 2010). Indeed, hybridization has been considered the rule rather than the exception at least in plants. During the recent decades, a number of studies related with the role of natural hybridization in shaping earth's biodiversity have been published (Wiesseman 2007). In this sense, it has been found that interspecific hybridization may have an important effect shaping the genetic diversity of a single population (Arnold 2006). Also, hybridization may be the cause of extinction of endemic species or rare plant populations (Levin and Francisco-Ortega 1996). In contrast, hybridization may lead to the creation of new species (Soltis \& Soltis 1993; Arnold 2006). Beyond the species level, hybridization may impact the arthropod community structure associated with hybridizing populations

\footnotetext{
*Correspondence: efrain_tovar@uaem.mx

'Departamento de Sistemática y Evolución, Centro de Investigación en Biodiversidad y Conservación, Universidad Autónoma del Estado de Morelos, Av. Universidad 1001, Col. Chamilpa, Cuernavaca, Morelos CP 62209, México Full list of author information is available at the end of the article
}

(Tovar-Sánchez and Oyama 2006) and lastly, it may affect some ecosystem processes (e.g. nutrient cycling due to the secondary metabolite composition of hybrids; e.g. Driebe \& Whitham 2000).

Recently, the movement of species far from their original distribution range has promoted the emergence of a number of invasive species (Mooney and Cleland 2001). Besides the concern that this species have in conservation biology due to their high competitive ability, this species may also cause the extinction of closely related species with restricted distribution range through introgressive hybridization (Vilà et al. 2000). Also, as hybridization creates new allelic combinations in the offspring, it has been proposed that hybridization may enhance the invasive capacity of an invasive species through gene introgression (Schierenbeck and Ellstrand 2009). As plant hybridization may have profound effects on the genetics and ecology of the participating species, the correct identification of hybrid individuals is of prime importance as a first step to specify which processes occur within hybridizing populations.

\section{Springer}


In this review, we aim to give a brief historical background of the study of plant hybridization as well as show the principal outcomes for the involved populations and their hybrid offspring. Then, due to the importance of hybrid individual identification, we explore several of the tools (morphological, chemical, DNA based markers) that have been employed for this purpose. We discuss their advantages and limitations in the recognition of hybrid individuals as well as the pattern of expression of each marker in hybrids.

\section{Review}

\section{Historical background of interspecific hybridization}

Plant hybridization has been important to humans since the Neolithic era, when the domestication of plants and animals began (Zirkle 1935). However, the formal study of plant hybridization was retarded due to the lack of knowledge about plant sexuality. Although hybridization between some species certainly occurred during domestication, these events passed unnoticed as there was no knowledge of pollen function. However, some cultures noticed that staminate flowers should be in close proximity to pistillate flowers in order to produce fruits in dioecious plants (Roberts 1929). For example, Babylonians were aware that hand pollination was necessary for reproduction of dioecious palms, identifying 'male' and 'female' plants. However, they did not recognize sex in plants because they had not a clear idea of fertilization. Also, as Babylonians cultivated palms to harvest the edible fruit rather than the seeds, the breeding of new plants was merely a matter of chance and thus, sexual reproduction remained unknown (Roberts 1929; Zirkle 1935).

Until the seventeenth century, the discussion about the existence of sex in plants was largely based on philosophical and moral discussions, with little experimental evidence. For example, Tabernaemontanus (1731) and other authors observed that grains of different colors occurred on the same ear of maize. However, they did not understand the mixture of grains, ascribing it to the creation of God in order to astonish the botanists of the time (Zirkle 1934). It was until 1694 that Camerarius proved experimentally that pollen is necessary for seed development, thus recognizing plant sexuality. Although he perceived the possibility of fertilizing a female plant with the pollen from another species, he never conducted hybridization experiments (Roberts 1929).

The first intentional hybrid produced is ascribed to Thomas Fairchild involving crosses between Dianthus spp. (Zirkle 1935). Although there is no record of the experiments by Fairchild himself, Bradley (1717) summarizes these experiments, noting that the hybrids were alike a 'mule' since they yielded no seeds. Also, Linnaeus performed several experimental crosses between Tragopogon species in 1759 . He found that hybrids sometimes have intermediate morphologies between the parental species (Roberts 1929). Additionally, Haartman also found that interspecific hybrids between Thalictrum sp. were intermediate regarding the number of stamens and pistils (Haartman 1764). So, by the mid of the eighteenth century, although poorly understood, plant hybridization was known as a phenomenon that could yield sterile plants with intermediate phenotypes.

However, it was Kölreuter who began with the systematic study of plant hybridization. This author performed crosses between Nicotiana paniculata and N. rustica (Kölreuter 1761). As a result from these crosses, he made important conclusions about plant hybridization. First, he observed that first generation (F1) hybrids usually exhibit pollen malfunction, describing them as 'botanical mules'. Second, Kölreuter made an important observation regarding ecological factors in the formation of hybrid individuals. He noted that hybrids were likely to occur when two closely related allopatric species are brought into sympatry by means of anthropogenic disturbance; resulting in hybrids with morphological intermediacy. When the hybrids obtained by Kölreuter were backcrossed with the parental species, the phenotype of the latters was recovered. He considered that hybrid sterility and the reversion to the parental phenotypes were a mean by which the preexisting harmony of nature could be conserved, considering hybrids as 'unnatural procreations' (Kölreuter 1761). Thus, he considered that hybridization was an ephemeral phenomenon with little importance, reinforcing the ideas of special creation of species prevailing at that time (Roberts 1929). By this time, all hybridization experiments were conducted by hand pollination. However, Kölreuter also noted that insect pollination occurred in a number of plants including the genus Iris, Nicotiana, Oenothera among others. Later, Sprengel (1793) described in great detail insect pollination in plants. Also, Sprengel found that the maturation of stamens and pistils within a same flower could exhibit temporal isolation. With this evidence, he suggested that these were mechanisms that maximize cross fertilization in plants, also noting that hybridization between different species pair could occur through insect pollination. Sprengel's work was influential to several authors such as Darwin (1859).

At the beginnings of nineteenth century, hybridization was largely used as a source of variation for plants of agronomical or ornamental importance. However, at this time, hybridization was mainly seen as a way to prove if two different plants deserve the species status (Roberts 1929). When plants of two presumably different species were crossed and fertile offspring was produced, then the two parental individuals were considered as varieties of a single species. On the contrary, if two plants were intercrossed and the resulting hybrid was sterile, the 
plants were considered as belonging to different species (e.g. Godron 1863). Most of the naturalists of the $19^{\text {th }}$ century considered sterility as a criterion for species status and hybrids were considered sterile by definition. This view was challenged by Hebert (1847) as he recognized that a continuum between species and varieties exists, with no discrete limits among them.

Following Hebert ideas, Naudin (1863) carried out interspecific crosses between Datura laevis and Datura stramonium. He observed that almost all hybrids were fertile, allowing him to grow further hybrid generations beyond F1. Naudin described the hybrids between Datura species as morphologically variable, exhibiting a 'disordered variation'. Sometimes they were morphologically intermediate and others they exhibited morphologies similar to either parental species. He also noted that F1 hybrids were always morphologically intermediate and were very similar among themselves, while later generation hybrids exhibited great variation. Other authors such as von Gärtner (1827), Knight (1799) and Nägeli (1865) also noticed this pattern. However, although they made similar inferences about character segregation described in 1865 by Mendel, they lack a mechanism to explain such variation. A very important finding in plant hybridization is the work by Mendel (1865). Despite of its importance, Mendel's paper was published in an obscure journal and thus, it passed unnoticed to the scientific community. However, the rediscovery of Mendel work by de Vries (1900), Correns (1900) and Tschermak (1900) set the foundation for modern plant genetics.

A couple years after the rediscovery of Mendel's laws, Sutton (1902) identified individual chromosomes in cells of Brachystola magna undergoing meiosis. He also noticed that the number of chromosomes was consistent in cells of a certain species, but the number of chromosomes varied among organisms. However, the most important discovery made by Sutton was that chromosomes were stable elements that pass from generation to generation, identifying the chromosomes as the genetic material responsible for Mendelian inheritance. This observations lead Sutton formulate the Chromosomal Theory of Inheritance, which provided the mechanism underlying Mendel's laws (Sutton 1902, 1903).

Once the mechanism of segregation of characters was discovered, plant hybridization became a very important mean to obtain new crop varieties. However, the evolutionary importance of hybridization was scarcely discussed. At the beginnings of the $20^{\text {th }}$ century, there were important discoveries that suggested the role of hybridization in evolution. Wingë (1917) showed through theoretical studies that new and stable species could arise by the duplication of the chromosome number of a hybrid individual (i.e., allopolyploidy). Nowadays, hybrid speciation through allopolyploidy is considered a prominent process within flowering plants (Soltis and Soltis 1993). Later, Müntzing (1930) proposed a second mechanism in which hybridization may produce new and stable species. Müntzing proposed that later generation hybrids may, by chance, lead to new combinations of alleles due to chromosome rearrangements producing populations that are homozygous for a unique combination of chromosome sterility factors (Müntzing 1930; Rieseberg 1997).

Also in the $20^{\text {th }}$ century, Anderson and his colleagues emphasized on the creative role of plant hybridization in evolution (Anderson 1949). Anderson suggested that, in natural conditions, hybrids may backcross toward their parental species, thus increasing the genetic diversity of the participating populations and contributing to adaptive evolution. Hybridization by this time was considered as a very frequent phenomenon in flowering plants (Stebbins 1959). In the last decades, the high number of molecular markers used to document hybridization have permitted to confirm several of the hypothesis proposed by Anderson. However, it has been also demonstrated that hybridization may have other consequences for the participating populations and their offspring (see further section).

\section{Hybridization, species concept, and phylogeny reconstruction}

As shown in the above section, several of the early investigators used hybridization as a way to prove or deny the species status of two supposedly different plant species. This criterion shows the difficulty in species' definition. This everlasting debate is exacerbated by genetic exchange (i.e., hybridization) between two different species. Although a discussion of the species concept is beyond the scope of this review, interspecific hybridization necessarily requires a consideration of species concept.

The biological species concept is one of the most widely used (Mayr 1942). This concept considers that species are a group of potentially or actually interbreeding organisms, emphasizing that the development of reproductive barriers is the main process by which species are defined (Mayr 1942, 1963). Mayr considered that hybrid zones were always stable resulting from a secondary contact. If the hybrids within this hybrid zones were fertile, then he considered that the two species should be considered subspecies. Alternatively, Mayr considered that hybrids always are sterile exhibiting a lower fitness and even when backcrosses may occur, they were considered unfit genotypes that were discarded by natural selection. Thus, hybridizing populations were seen as an intermediate step of speciation (Dobzhansky 1940, 1970). The study of hybrid zones were important in order to clarify the steps in speciation that yield to complete reproductive isolation between taxa (i.e., reinforcement). Although reinforcement is an important consequence of natural hybridization, it is not the only one; hybrid speciation, 
introgression and genetic assimilation may also occur. So, how can we recognize these consequences and still consider the participating taxa as different species?

One way to achieve this is by relaxing the definition of hybridization itself. Hybridization is commonly considered as the cross fertilization between individuals of different species. However, a broader definition considers hybridization as the cross fertilization of individuals from populations that are distinguishable on the basis of one or more heritable characters (Harrison 1990; Arnold 1997). In the same sense, introgression is typically considered as the movement of genes between species through repeated backcrossing. A broader definition of introgression involves the movement of genes between genetically distinguishable populations (Rieseberg and Carney 1998). These definitions of hybridization and introgression have the advantage of not relying upon any species concept. Thus, under this definition hybridization may occur between species, subspecies or between differentiated populations of a single species.

Another way to recognize hybridizing taxa as species is relying upon the cohesion species concept as described by Templeton (1989). This concept arose in order to overcome the limitations of the biological species concept to recognize asexual organisms as well as those involved in syngameons. Under this concept, a species is defined as 'the most inclusive group of organisms having the potential for genetic and/or demographic exchangeability' (Templeton 1989). This definition includes the ecological and genetic characteristic of the species, which gives as a result a cohesive group. The genetic characteristics that this concept takes into account include, of course, hybridization and genetic exchange between divergent lineages. Also, this concept does not consider hybridizing taxa as a subspecific taxa. This concept takes into account hybridization as part of the evolutionary history of a certain taxon (Templeton 1989).

We may also recognize hybridizing species when relaxing the biological species concept. In this regard, Rieseberg and Carney (1998) define a biological species as "groups of interbreeding populations that are 'genetically isolated' rather than 'reproductively isolated' from other such groups". According to the authors, this definition allows the recognition of hybridizing taxa as different species. The authors consider that most hybrid zones act as a barrier to genetic exchange among species, thus each species will preserve its genetic integrity, permitting their differentiation by genetic means (Rieseberg and Carney 1998).

Besides the problem of the species concept that should be employed to define hybridizing taxa, the genetic exchange between differentiated species may also pose a problem in systematics during the phylogeny reconstruction of a certain lineage (Arnold 2006). In this sense, there are two approaches when including hybrids in phylogeny reconstruction. The first of these approaches employ explicitly the phylogeny reconstruction as a tool for detecting hybridization or as a tool to prove the hybrid origin of a species (van Ramsdonk et al. 2000; Koontz et al. 2004; Soltis et al. 2008). Also, hybridization could be suggested to occur between a species pair when an incongruence in the topology of the phylogenies derived from different data sets occur (nuclear vs. cytoplasmic markers; Rieseberg and Soltis 1991; Pelser et al. 2010). However it is emphasized that phylogeny incongruence may be the result of processes other than hybridization such as incomplete lineage sorting (Comes and Abbott 2001; Pelser et al. 2010). Despite this difficulty, in these studies there is an a priori knowledge of hybrid taxa or putative hybrid individuals.

The second approach, deals with the real problem when including hybrids in a phylogeny. In this case, there is no a priori knowledge of the inclusion of hybrids in the analysis. It has been proposed that the inclusion of hybrids may impact importantly the topology of the phylogeny, distorting the hypothesized relationships between nonhybrid taxa (Rieseberg et al. 1995). However, under certain conditions, this is not necessarily the case. For instance, McDade $(1990,1992)$ tested the impact of the inclusion of F1 hybrids of several species of Aphelandra in the topology of phylogenies employing morphological data. He concluded that the inclusion of hybrids between closely related species do not alter the topology of the phylogeny, while the inclusion of hybrids between distantly related species within the genus have a very important impact in the topology of the phylogeny and distort the relationships between non hybrid-taxa (McDade 1990, 1992). Also, she found that hybrids are usually grouped in a clade where one of the parental species occurs, but rarely with both (McDade 1992). In a similar fashion, Soltis et al. (2008), evaluated the impact of the inclusion of hybrid's polymorphic sequences of ribosomal DNA (rDNA) spacers in the topology of phylogenies of Tragopogon, Glycine and Rubus. In general the authors found that the inclusion of hybrids do not disrupt the overall topology of the phylogenies, conserving the relationships between non-hybrid taxa. However, McDade (1992) and Soltis et al. (2008) outline that cladistics analysis based on rDNA spacers and morphology may be an unreliable method to distinguish between hybrid and non-hybrid taxa, making necessary the use of additional data to unveil the phylogeny of a group. Therefore, the authors suggest that hybridization may be a source of error during cladistic analysis (McDade 1992; Soltis et al. 2008).

\section{Outcomes of plant hybridization}

Natural hybridization is nowadays recognized as a frequent phenomenon among vascular plants. Whitney et al. (2010) studied the frequency and patterns of interspecific hybridization across eight floras. The authors found that 
$40.4 \%$ of the families and $16.2 \%$ of the genera studied reported at least one hybrid. However, the consequences of these hybridization events may have a variety of consequences for the hybridizing taxa and their hybrids. These consequences depend on the environmental conditions (i.e., degree of disturbance), the local abundance of the parental species and the genetic structure of the participating species (Levin and Francisco-Ortega 1996; Rhymer and Simberloff 1996; Arnold 2006). A remarkable consequence of plant hybridization is the high frequency of hybrid species reported (Rieseberg 1997). It has been suggested that up to $11 \%$ of flowering plants may be directly the result of hybridization events owing to the high levels of polyploidy found in angiosperms (Arnold 2006). Also, there are several studies that report the occurrence of speciation via hybridization in which the newly formed species shows the same ploidy of the parental species (Rieseberg 1997).

However, in several studies it has been found that although hybridization may occur between a species pair, the resulting first generation hybrids (F1) exhibit a low reproductive success measured as pollen fertility (e.g. Campbell et al. 2003), leading to 'botanical mules' (sensu Kölreuter). The production of these unfit F1 has been proposed as a mechanism of reinforcement of the reproductive barriers between the participating species due to selection against hybrid genotypes (Marshall et al. 2002). However, in most cases, the fitness of hybrid individuals appears to be dependent on the environment in which they establish. In this sense, a number of studies (Levin and Francisco-Ortega 1996; Lamont et al. 2003; Lihová et al. 2007; Tucker \& Behm 2011) have reported a high occurrence of hybrids in environments with a high degree of disturbance (along roadsides, crops, sites with recent volcanic activity, etc.). The role of disturbance in plant hybridization is twofold:

1. A major isolating mechanism between potentially hybridizing species is a divergence in the habitat preferences between species (Arnold 2006). Disturbance usually breaks down this isolating mechanism by creating environments where both species can establish and reproduce.

2. Once hybridizing species meet, hybrid genotypes may be produced in the absence of other isolating mechanisms (i.e. incompatibility). In this disturbed environments, certain hybrid genotypes may exhibit a similar or higher fitness than both parental species (Mallet 2005). Thus, it has been considered that disturbance is a prerequisite to the formation of hybrid zones (e.g. Rieseberg and Gerber 1995).

Once F1 individuals are formed, they may act as a bridge whereby alleles may cross from one species to another through repeated backcrossing with the parental species (i.e., introgression). If the rate of backcrossing is limited and the abundance of the parental species is similar, introgression may lead to an increase of the intraspecific genetic diversity of the parental species, which may enable them to colonize new areas (e.g., Caraway et al. 2001). However, when the abundance of the parental species differ considerably, the introgression towards the less abundant species may lead to the loss of its genetic integrity, leading to its extinction through the process known as 'genetic assimilation' (Levin and FranciscoOrtega 1996; Meyerson et al. 2010). In this regard, the introduction of species far from its native range has resulted in the formation of invasive species (Vilà et al. 2000; Petit et al. 2004; Schierenbeck and Ellstrand 2009). In addition to the threat of invasive species to local biodiversity due to their high competitivity, they may also pose a serious threat to endemic or rare populations of species by means of genetic assimilation, especially in environments with a high degree of disturbance. Also, it has been proposed that hybridization may enhance the invasive behavior of certain species, leading to highly competitive genotypes with increased invasive behavior (Schierenbeck and Ellstrand 2009). As shown above, natural hybridization may have a number of consequences that may affect either positively (e.g., increased allele diversity, speciation) as well as negatively (e.g., extinction through genetic assimilation, increased invasiveness of certain genotypes) the genetic diversity of a taxon or the species composition of a certain community. Thus, as a first step in the study of this processes, it is of chief importance to make a correct identification of hybrid individuals. In the following sections, we discuss the morphological, chemical and DNA based markers used for hybrid identification.

\section{Morphological character expression in hybrids}

Traditionally, taxonomist rely upon intermediate morphology of hybrids compared to their parental species for their identification. An intermediate morphology was an intuitively assumed characteristic of hybrids as these characters were supposed to be in polygenic control with simple additive effects (Rieseberg et al. 2007). In fact, most of the methodologies employed in the past century were designed to detect this intermediate morphology. Within these methodologies, Anderson (1949) and other influential authors employed methods such as pictoralized scatter diagrams (Anderson 1949), multivariate analysis such as principal component analysis (Wagner 1969) and the character count procedure (Wilson 1992). All the authors suggest that these methodologies should be employed with a large data set with as much morphological characters as possible (Anderson 1949; Wilson 1992). Also, it was supposed that the correlation between 
the morphological characters in the parental individuals will be conserved in hybrid individuals. This 'character coherence' of morphological traits, was considered a diagnostic feature of hybrid individuals (Anderson 1949). However, when morphological intermediacy or character coherence were lacking in hybrid individuals, it was rarely discussed.

Later, it was recognized that morphological character intermediacy is a poor predictor of hybrid ancestry by several reasons:

1. Morphological characters are usually correlated. Thus, the number of available characters is much reduced.

2. As any other phenotypic character, the morphological expression in hybrids is highly dependent on the environment. In this sense, the same genotype may exhibit a wide array of morphologies (intermediate or not) if grown in different conditions.

3. Also, morphological intermediacy may be originated by processes other than hybridization. For example, some individuals of closely related species may exhibit morphological intermediacy if these species retain plesiomorphic character states of their ancestral population, conducing to an erroneous interpretation of hybridization (Rieseberg 1995; Judd et al. 2002; Arnold 2006).

Also, from the genetic point of view there are also explanations from a deviation of morphological intermediacy. In a revision of 46 studies exploring morphological character expression in hybrids, Rieseberg and Ellstrand (1993) pointed out that F1 hybrids expressed $44.6 \%$ of intermediate characters, while $45.2 \%$ of the characters in hybrids were similar to either parental species. Lastly, $10.2 \%$ of the characters showed values beyond the range of the parental species (transgressive characters). The high frequency of parental values in hybrids may be the result of only one ore few loci having a dominant (rather than codominant) effect on a certain morphological character in hybrids. However, the most outstanding result is the presence of ca. $10 \%$ of transgressive character in F1 individuals (Rieseberg and Ellstrand 1993). In advanced hybrid generations (F2, backcrosses) the percentage of transgressive characters was ca. $30 \%$. The occurrence of the transgressive characters have been ascribed to an increased mutation rate in hybrids, the complementary action of new allele combinations in hybrids, reduced developmental stability, epistatic effects, heterosis, among others (Grant 1975; Voigt and Tischler 1994; Rieseberg et al. 1999; Bell and Travis 2005). As several of this explanations are not genetically inherited traits (epsitasis, heterosis, developmental instability), they account for a small fraction of the variation. So, it is assumed by a number of authors that transgressive character expression is the result of a complementary action of genes (Rieseberg et al. 2003; Bell and Travis 2005; Stelkens and Seehausen 2009).

Complementary gene action assumes that the parental species have fixed alleles with opposing effects within the hybrid (Rieseberg et al. 1999). This is, transgressive character expression in hybrids results comes from loci interactions between alleles having opposing effects on phenotypes within each parental species but have reinforcing effects (i.e., complementation) in hybrids (Bell and Travis 2005; Table 1). This model of transgressive character inheritance explains the larger amount of transgression found in later generation hybrids compared to F1 hybrids, where intermediate character expression is more frequent due to an additive effect of the parental loci (Table 1).

The frequency of transgressive character expression in hybrids seems to be the rule in plants. From a survey of 113 studies reporting hybrid phenotypic values, Rieseberg et al. (1999) found that only three of these failed to report at least one transgressive character. Also, of 579 morphological traits measured in these 113 studies, 58\% exhibited transgressive values. Due to this unpredictable morphological expression in hybrids, some authors have considered that these are of limited value in detecting hybridization (Rieseberg and Ellstrand 1993; Hardig et al. 2000, Arnold 2006), and additional markers should be employed to make robust hypothesis of hybridization.

\section{Secondary metabolite expression in hybrids}

Given that morphological markers are of limited importance as tools for hybrid recognition, other markers have

Table 1 Hypothetical case of transgressive segregation of a quantitative morphological trait due complementary gene action

\begin{tabular}{|c|c|c|c|c|c|}
\hline \multirow{3}{*}{$\begin{array}{l}\text { Locus } \\
1\end{array}$} & \multicolumn{5}{|c|}{ Phenotypic value } \\
\hline & \multirow{2}{*}{$\begin{array}{c}\text { Species A } \\
+1,+1\end{array}$} & \multirow{2}{*}{$\begin{array}{c}\text { Species B } \\
-1,-1\end{array}$} & \multirow{2}{*}{$\begin{array}{c}\mathbf{F 1} \\
+1,-1\end{array}$} & \multicolumn{2}{|c|}{ Transgressive F2 hybrids } \\
\hline & & & & $+1,+1$ & $-1,-1$ \\
\hline 2 & $+1,+1$ & $-1,-1$ & $+1,-1$ & $+1,+1$ & $-1,-1$ \\
\hline 3 & $-1,-1$ & $+1,+1$ & $+1,-1$ & $+1,+1$ & $-1,-1$ \\
\hline 4 & $-1,-1$ & $+1,+1$ & $+1,-1$ & $+1,+1$ & $-1,-1$ \\
\hline Net phenotypic value & 0 & 0 & 0 & +8 & -8 \\
\hline
\end{tabular}


been historically employed for this purpose. Among these, the secondary metabolite composition of hybrids was considered as a more reliable tool. In the mid 1950's and until 1980, the use of this markers was thoroughly employed in phylogenetic and in taxonomic studies of several species (La Duke 1982; Rieseberg and Ellstrand 1993). Zobel (1951) was the first to apply the secondary chemistry in hybrid recognition. However it was with the studies of Alston and Turner (1962) that this approach was widely recognized.

The secondary metabolite composition in hybrids was thought to be a reliable tool for hybrid identification because it was supposed that they had a simple inheritance mechanism (i.e. oligogenic control with Mendelian segregation ratios). However, as shown later, hybrid secondary metabolites usually have more complex patterns of inheritance in hybrids both qualitatively and quantitatively (Orians 2000; Cheng et al. 2011). The main secondary metabolites studied in hybrids have been phenolic, terpenoid, alkaloid, isothiozyanates and flavonoid compounds. Of these, the flavonoid compounds have been the most studied compounds due to their high variability and stability (Crawford and Giannasi 1982; Rieseberg and Ellstrand 1993).

\section{Qualitative variation and its genetic basis in hybrid secondary metabolite expression}

Rieseberg and Ellstrand (1993) compile 24 studies about plant secondary metabolite expression in hybrids. As a result of this revision, the authors found that first generation hybrids (F1) usually exhibit a complementary expression of the secondary metabolites present in the parental species. That is, the hybrid usually expresses both parental secondary metabolites. Rieseberg and Ellstrand (1993) found that $67.7 \%$ of F1 hybrids exhibit this complementary pattern, while $27 \%$ lack at least one secondary metabolite present in the parental species and $5.2 \%$ express new metabolites which are not present in their progenitors.

More recently, Cheng et al. (2011) complemented the revision of Rieseberg and Ellstrand (1993) by incorporating the patterns found by Orians et al. (2000) and other studies done until 2011. The findings of these authors follow the same general pattern above mentioned. In total they revised the expression of 1,112 secondary metabolites and their expression in hybrids: $70.3 \%$ of these metabolites were present in both the parental species and their hybrids, $24.2 \%$ of the metabolites were lacking in hybrid progeny and $5.5 \%$ were new metabolites not present in the parental species.

It has been proposed that the expression of metabolite secondary compounds is regulated by one or few genes exhibiting dominance/recessivity (where dominance is given by the expression of a secondary metabolite) which follow the Mendelian segregation ratios. This pattern of inheritance explain the complementarity found in hybrid metabolite composition. However, it is clear that deviations of this general pattern exist. This deviations may be explained in several ways:

1. The lack of a parental secondary metabolite in hybrids may be due to the polymorphism in the loci controlling the expression in parental individuals. If the parental individuals of a hybrid are heterozygous for a gene controlling the expression of a secondary metabolite, their hybrid progeny may or not exhibit such metabolite (according to Mendelian inheritance).

2. Also, the lack of a secondary metabolite in hybrids may be due to the elongation of the biosynthetic pathway. The elongation in a certain pathway may yield a secondary metabolite which is an intermediary to another pathway, being rapidly converted to the next compound in the pathway.

3. The expression of new secondary metabolites may be due to the obstruction of a biosynthetic pathway in hybrids. If this occurs, the accumulation of intermediary compounds that are only transient in the parental species will be evident in hybrids (Rieseberg and Ellstrand 1993; Orians 2000; Firn and Jones 2003; Cheng et al. 2011).

Because of this, in large populations where hybridization occurs, it is expected that a large qualitative variation of secondary metabolite compounds will occur. This high variability of secondary metabolite has been observed in a number of studies (e.g., Hallgren et al. 2003; Kirk et al. 2004; Oberprieler et al. 2010; Oberprieler et al. 2011).

\section{Quantitative variation and its genetic basis in hybrid secondary metabolite expression}

As with the qualitative variation, the quantitative patterns of the secondary metabolite expression in hybrids is variable. Orians (2000) evaluated the concentration of secondary metabolites found in hybrids in relation to the levels present in the parental individuals (5 studies). As a result, the author found that 33\% of the 96 secondary metabolites were expressed at similar concentrations of the parents, $29 \%$ showed intermediate concentrations in hybrids, $19 \%$ were at higher concentrations in hybrids (overexpressed) and 14\% showed lower concentrations than their parents (underexpression). Recently, Cheng et al. (2011) extended this revision by adding 7 studies published until 2010. The authors found a similar pattern: most of the metabolites are expressed at similar concentrations of one or both parents or at intermediate concentrations (51.6 and $28.2 \%$ respectively). Also, some metabolites are overexpressed (11.5\%) or underexpressed (8.7) in hybrids. 
The genetic regulation of the quantitative expression of secondary metabolites in hybrids is controlled by more than one gene with dominant, overdominant or epistatic effect within a locus (Cheng et al. 2011). The effects of this genes usually affect the expression of the enzymes involved in the pathway of secondary metabolites. If the enzyme is overexpressed, so will happen to the secondary metabolites. Although the metabolite secondary concentration of hybrids is rarely used as a criterion for hybrid identification, it may impact plant-herbivore interactions and other ecological processes (see further discussion).

\section{Genetic data employed for hybrid recognition:} chromosome number and DNA fingerprinting techniques Besides phenotypic characters, hybrid recognition relies nowadays in the genetic data of individuals. In this sense, one approach that was thoroughly used as an important evidence of hybridization during the $20^{\text {th }}$ century was the chromosome number of putative hybrid individuals. This approach supposes that hybrid individuals always undergo an instant duplication of the chromosome complement (i.e. allopolyploidy; Harlan and deWet 1975). Several well known cases of allopolyploidy include hybrids between Tragopogon spp (Ownbey 1950; Roose and Gottlieb 1976), Spartina spp (Strong and Ayres 2013), and species belonging to the Hawaiian silversword alliance (Barrier et al. 1999; Lawton-Rauh 2003) among others. This tool became popular because the analysis of the chromosome number in hybrids was supposed to be relatively easy; hybrids will display a duplication of the whole chromosome complement when compared with the putative parental species. Also, the discovery of allopolyploidy was quite important, since it provided a mechanism that lead to reproductive isolation between hybrids and its parental species (Winge 1917; Ownbey 1950). Indeed, polyploidy is nowadays considered a prominent speciation mechanism in flowering plants (Levin 1983; Ramsey and Schemske 1998; Soltis et al. 2010).

However, in some cases it may be difficult to distinguish between autopolyploidy (i.e., polyploids that arise within a single population of a single species; Grant 1981) and allopolyploidy (i.e., polyploids derived from hybridization between two different species; Ramsey and Schemske 1998), rendering the chromosome number as an unreliable tool for hybrid detection (Comai 2005). This difficulty arises because intermediate states between autopolyploidy and allopoliploidy may occur, making difficult the differentiation between these categories. It has been proposed that 'segmental allopolyploids' may occur, in which some chromosomes may exhibit a pairing similar to those of allopolyploids during meiosis, and other chromosomes have a similar pairing to autopolyploids (Stebbins 1950). Although no clear examples of the occurrence of segmental allopolyloids can be mentioned (Soltis et al. 2010), this condition explains some segregation ratios found in nature (Stift et al. 2008). Besides this problem, the differentiation between auto- and allopolyploids pose some methodological difficulties. In order to establish whether an individual is an auto- or an allopolyploid, an exploration of the segregation ratios at many loci as well as the absence or presence of multivalents during meiosis should be observed (Soltis et al. 2010). This techniques are expensive and time-consuming, making them ineffective to determine the status of putative hybrid individuals.

As mentioned above, the chromosome number of putative hybrids may give insights of hybridization in some instances. However, when it is used in the absence of additional data (morphological or genotypic), the frequency of hybridization may be underestimated. This occurs because hybrids may exhibit the same chromosome number than the parental species (i.e., homoploid hybrids; Mallet 2007, Abbott et al. 2010). Indeed, despite that allopolyploidy is considered a prominent mode of speciation within angiosperm, homoploid hybrid speciation has been recorded in a number of species (Gross and Rieseberg 2005; Abbott et al. 2010). Because of this, the chromosome number of hybrids is not a reliable tool when used in the absence of additional data, however it may provide robust hypothesis of hybridization when morphological or DNA fingerprinting techniques are employed (e.g., Newaskar et al. 2013)

Due to the complex pattern of expression of phenotypic data and the unreliable data provided by chromosome number counts in putative hybrids, DNA fingerprinting techniques are now the most used tool for hybrid identification. The advantages that these markers have over phenotypic traits are: 1 ) they are present in a large number within the genome, 2) they usually exhibit independence, 3 ) as these markers are supposed to be located in noncoding regions, they are selectively neutral, and 4) their inheritance is strictly under Mendelian segregation ratios (Rieseberg and Wendel, 1992). Also, these markers have been useful detecting different hybrid classes (F1, F2, backcrosses and later generation hybrids) when Bayesian based analyses such as STRUCTURE (Pritchard et al. 2000), NEWHYBRIDS (Anderson and Thompson 2002), BAPS (Corander and Marttinen 2006) and GENECLASS (Piry et al. 2004) have been employed.

However, there is a wide variety of DNA fingerprinting techniques employed for hybrid recognition. In Table 2, we mention the main DNA fingerprinting techniques, their mode of inheritance and degree of polymorphism. Within the non-based PCR techniques the Restriction Fragment Length Polymorphism (RFLPs) is the most recognized technique (Jeffreys et al. 1985). This technique is based on the activity of bacterial restriction enzymes. These enzymes identify specific palindrome sequences, producing fragments with variable dimensions. This 
Table 2 Comparison of several DNA-based markers used for hybrid identification

\begin{tabular}{|c|c|c|c|c|}
\hline Marker & Degree of polymorphism & Inheritance & Reproducibility & Technical requirements \\
\hline RAPD & Medium & Dominant & Low & Low \\
\hline RFLP & Medium & Codominant & High & High \\
\hline AFLP & Medium & Dominant & High & High \\
\hline SSR & Medium & Codominant & Medium & Medium \\
\hline SNP & High & Codominant & High & Medium \\
\hline
\end{tabular}

RAPD, random amplified polymorphic DNA; RFLP, restriction fragment length polymorphism; AFLP, amplified fragment length polymorphism; SSR, single sequence repeats; SNP, single nucleotide polymorphism.

fragments are then visualized on gel electrophoresis (Jeffreys et al. 1985). The variation in the length of restriction fragments are due to changes (point mutations or translocations) in the sequence recognized by the enzymes. Although RFLP are highly reproducible and polymorphic, this technique is time consuming. Also, the use of radioactive agents and the need for large quantities of sample DNA make this technique unpopular nowadays.

Several PCR-based markers overcome some of the difficulties of RFLPs. PCR based markers are less time consuming techniques, and the initial DNA sample could be minimal. Also, some of these techniques require no previous knowledge of sequence of the organism under study. Random Amplified Polymorphic DNA (RAPD) and Amplified Fragment Length Polymorphism (AFLP) are two of these markers (Williams et al. 1990; Vos et al. 1995). RAPD markers are generated through the random amplification of genomic DNA using short primers (10 base pair). The use of short primers is necessary to increase the probability that they are able to find homologous sequences suitable for annealing. The polymorphism in RAPD fragments is produced by rearrangements or deletions at the primer binding sites in the genome (Williams et al. 1990). However, the major problem with this technique is its poor reproducibility, usually exhibiting different banding pattern when carried out under slightly different PCR conditions (Williams et al. 1990; Hadrys et al. 1992). AFLP are a much reproducible technique which combine RAPD and RFLP. In this technique, restriction fragments of the sample DNA are obtained. Then, the fragments are amplified through random PCR amplification (Vos et al. 1995). The main limitation of both RAPD and AFLP fragments is that both have a dominant pattern of inheritance. That is, the character is recorded as the presence of a specific band in gel electrophoresis (dominant state) or the absence of such band (recessive state).

A different approach to arbitrary PCR amplification consists in the amplification of target regions of a genome through specific primers. These kind of DNA fingerprinting techniques have become very popular due to the ease and accessibility of sequence technology. A popular technique relies in the polymorphism of Microsatellite or
Simple Sequence Repeats (SSR). SSR consist of sequences of repetitions, comprising short motifs generally between 2 and 6 base-pairs long (Kalia et al. 2011). The polymorphism within a specific locus is due to the variation in length of the microsatellite sequence, which depends on the number of repetitions of the basic motif. These markers have several advantages compared to AFLP, RAPD and RFLP. SSR have a codominant inheritance (i.e., the heterozygote state for a locus can be assessed), they are highly abundant in the genome, they exhibit a high allelic diversity and their amplification is highly reproducible (Kalia et al. 2011). However, SSR require extensive knowledge of DNA sequence of the target species in order to design specific primers. Also, the presence of null alleles (i.e., a point mutation in the primer annealing site may cause the amplification failure of a specific microsatellite locus) is thought to be frequent, leading to an underestimation of allele diversity (Chybicki and Burczyk 2009).

The techniques mentioned so far have been widely employed for hybrid recognition (Blair and Hufbauer 2010; Meyerson et al. 2010; Travis et al. 2010; Zalapa et al. 2010; Saad et al. 2011; Tovar-Sánchez et al. 2012). However, the new technological advances in sequencing technology have provided with new markers with an almost unlimited amount of variation based on DNA sequences. The main problem with classical protocols employing previous markers such as RAPD, SSR, AFLP, and RFLP is that they have a low availability of markersb that discriminate between closely related species with low resolution and identify later generation hybrids (Twyford and Ennos 2012). Although a recent hybridization event can unequivocally detected with as few as four markers (Boecklen and Howard 1997), the correct assignment of individuals to hybrid categories (F1, F2, backcrosses) will require the exploration of 24 to 48 independent codominant loci (Vähä and Primmer 2006). Also, it is sometimes difficult to find diagnostic or species-specific markers (Howard et al. 1997) which differentiate between hybridizing species using the traditional PCR based methodologies. This diagnostic markers are the most powerful markers used to detect late generation introgression (Hohenlohe et al. 2011). 
These limitations in most PCR based DNA markers have conducted to the development of new markers that assess the sequence of a complete subsection of a genome without the need of previous knowledge of the target sequence. In particular the new technique known as NextGeneration Sequencing (NGS) generates a large quantity of nucleotide sequence data from complex nucleic acid populations (Metzker 2010). NGS is considered an emerging technique which is thought to improve our knowledge about hybridization and introgression because no prior knowledge of the sequence of the target organisms is required (Hohenlohe et al. 2011). In particular, the vast amount of markers for each of the parental hybridizing populations may increase considerably (up to ca. 300), compared to the traditional PCR based methods above mentioned (Twyford and Ennos 2012).

\section{Why should we employ several different markers for hybrid identification?}

In the previous sections, we discussed the principal tools for hybrid identification. It is clear nowadays that DNA fingerprinting techniques are the most reliable tool for hybrid identification compared to morphological and secondary metabolite markers. The main advantages of DNA molecular markers are principally their neutrality and the nearly unlimited number in which they can be found within the genome. As mentioned earlier, morphological character expression is considered complex and in some cases unpredictable (Rieseberg et al. 1999; Hardig et al. 2000). Meanwhile, secondary metabolites have a more predictable inheritance mechanism, with F1 hybrids exhibiting both secondary metabolites of the parental species (Rieseberg and Ellstrand 1993; Orians 2000; Cheng et al. 2011). However, obtaining the chemical profile of hybrids is time consuming and is technically difficult. Also, it is a poor predictor of hybrid ancestry in later generation hybrids (Cheng et al. 2011). Finally, chromosome number may provide information about the hybrid origin of individuals when these exhibit allopolyploidy, however, sometimes hybrids exhibit a homoploid condition compared to its parental species (Abbott et al. 2010). Also, the chromosome count of putative hybrids and parental individuals may be expensive and time consuming.

So, if DNA fingerprinting techniques are the best tools for hybrid recognition, why should researchers continue using other markers such as morphological, chemical profiles and chromosome number in hybridization related studies? Some authors propose that besides DNA fingerprinting, other markers should be employed in order to have a vast amount of evidence to confirm the hybridization hypothesis between two taxa (e.g. Hardig et al. 2000). Also, it has been found that these additional markers may unveil hybrid individuals that go undetected when using problematic DNA markers such as
RAPD or AFLP (e.g., Kirk et al. 2012). However, the main reason to study phenotypic and chromosomal traits in hybrids is that they may give insights of their ecological performance. This is of special importance when hybrids exhibit novel or transgressive characters compared to their parental species.

In this regard, the expression of transgressive morphological characters have been proposed as a mechanism of speciation when ecological divergence occurs between the parental species and their hybrids. In this regard, Schwarzbach et al. (2001) studied the character expression of the hybrid species Helianthus anomalus and their parental species; $H$. annuus and $H$. texanus. The hybrid species has a very distinct ecological preference than their parental species. H. anomalus occurs mainly in sand dune habitats. As a first step, the hybrid species was determined as such employing DNA based markers (Rieseberg 1991). But later, Schwarzbach et al. (2001) accounted its morphological variation. The authors measured 41 morphological traits. They found that H. anomalus was intermediate in $2.4 \%$ of the characters, while parental and transgressive characters accounted for $56.1 \%$ and $41.5 \%$. The authors suggest that the high frequency of transgressive character expression of $H$. anomalus may have facilitated its ecological divergence. This hypothesis is reinforced as many of this transgressive characters are consistent with adaptations for other sand dune plants (Schwarzbach et al. 2001).

Besides the role of hybridization in speciation above mentioned, natural hybridization has also been proposed as a process involved in the evolution of invasive genotypes due to its potential in generating evolutionary novelty (Schierenbeck and Ellstrand 2009). The transgressive character expression in some hybrid genotypes has been proposed as one of the mechanisms that enhance invasiveness in some populations (Ellstrand and Schierenbeck 2000).

On the other hand, the secondary metabolite expression in hybrids may affect he herbivore-plant interaction. In this sense, the quantity and the type of the secondary metabolites present in hybrid individuals may reduce the palatability to herbivores (Orians 2000). In terms of the qualitative variation, the expression of new metabolites in hybrid could deter nonadapted herbivores, both generalists and specialists thus generating resistant plants. Whether these hybrids remain resistant might depend upon the relative abundance of the plant. Chew and Courtney (1991) argue that if the abundance of a host plant producing a novel chemical is highly variable over time, herbivores will be unable to track the plant and adapt to that chemical. In terms of quantitative variation hybrids may exhibit a higher concentration of secondary metabolites. In general, it has been proposed that a high concentration of secondary metabolites give resistance 
to hybrid individuals (Orians 2000). However, a single chemical might stimulate, deter or have no effect in the activity of an herbivore (Orians 2000). Thus, the quality and quantity of hybrid secondary metabolites may influence the arthropod associated community and the herbivore-plant interaction.

However it has been suggested that hybrid secondary metabolite composition may alter processes at the ecosystem level. For example, Driebe and Whitham (2000) evaluated the leaf litter decomposition rate of Populus angustifolia, P. fremontii and their hybrids. In general, the authors found that F1 hybrids showed all secondary metabolites present in the parental species. The leaf litter decomposition rate of F1 hybrids was intermediate between both parental species. However, they found that backcross hybrids showed higher levels of condensed tannins than both pure parental individuals and F1 hybrids, which lead to a slower decomposition rate of the leaf litter. The authors suggest that if hybridization occurs in broad geographic areas, the nutrient availability in the soil could be seriously altered due to the altered decomposition rate, modifying whole ecosystem processes (Driebe and Whitham 2000).

Regarding chromosome number, several hybridization related studies continue to study the cytogenetic of putative hybrid individuals (e.g. Suárez-Santiago et al. 2011). The approach of these studies may answer several important questions about hybrid performance. First, hybridization may produce allopolyploids that are intersterile to both parental species and may yield to new species (Comai 2005). On the other hand, if hybrids are homoploid, they may backcross toward parental species and lead to introgression (e.g., Peffley and Mangum 1990). However, although homoploid hybrids may be interfertile with both parental species, homoploid hybrid speciation may occur. Homopoid hybrid speciation may occur in two ways; 1 ) homoploid hybrids may exhibit new characteristics (i.e., transgressive characters) that enable them to colonize new areas, leading to an ecological divergence from parental species or 2) hybrids may exhibit new chromosome or genetic sterility barriers that lead to reproductive isolation from their parental species (Abbott et al. 2010). Homoploid hybrid speciation has been proposed to produce several species such as H. anomalus (Sapir et al. 2007), H. paradoxus (Lexer et al. 2003) and H. deserticola (Gross et al. 2003).

Also, allopolyploids may have also important features that yield to evolutionary novelty. Allopolyploids exhibit some advantages compared to their diploid parental species. For instance, polyploids usually exhibit heterosis, causing them to be more vigorous than their parental species (Chen 2013). Also, due to the chromosome doubling in allopolyploids, hybrids exhibit gene redundancy which provide them of several advantages. First, gene redundancy in allopolyploids provide them with a protection against recessive deleterious alleles and recessive mutations (Comai 2005). Second, allopolyploids are able to diversify gene function by modifying the redundant copies of genes. This may lead to advantageous alleles that may increase their fitness (Prince and Pickett 2002; Adams et al. 2005). Finally, allopolyploids usually show an increase of asexual reproduction that enable them to increase their population even in the absence of sexual mates (Comai 2005). Spartina anglica is a remarkable example of the advantageous characteristics offered by allopolyploidy (see Strong and Ayres 2013). Due to the importance of allopolyploidy and homoploidy in the ecological performance of hybrids, it is not trivial to study the chromosome number of putative hybrid individuals.

As shown in a previous section, morphological markers, chemical markers and chromosome number are not reliable tools for hybrid identification when used in the absence of DNA fingerprinting techniques. However, the evaluation of these markers is of importance due to the evolutionary novelty that may arise via hybridization. Hybrids may exhibit transgressive character expression in morphological characters, new secondary metabolites and enhanced genetic variability due to allpoliploidy. This evolutionary novelty may result in new species if ecological divergence occurs or it may lead to an increase of hybrid resistance to herbivores or pathogens. Although DNA fingerprinting techniques are the most reliable tool for hybrid identification, the use of additional markers will continue to be employed as they give insights of the ecological performance of hybrids.

\section{Conclusions}

In this review we explored the utility and/or mode of inheritance of the main markers that have been historically employed for hybrid identification: morphological and chemical markers as well as chromosome number and DNA fingerprinting techniques. While morphological characters were thoroughly employed during the last century as the main marker for hybrid recognition, nowadays it is known that their pattern of inheritance is complex and usually unpredictable. Also, during the last century, the plant secondary metabolite composition emerged as a more reliable tool than morphological markers, however, their high costs, their low polymorphism and complex inheritance made them also unreliable tools for hybrid recognition in the absence of other markers. As both chemical and morphological markers are phenotypic traits, their expression in hybrids is highly dependent of the environment, reducing their utility to detect hybridization under natural conditions. Also, the chromosome number of putative hybrids is a criterion that may exhibit some disadvantages. Some hybrids may exhibit allopolyploidy, while others may be 
homoploid hybrids. Thus, hybridization rates may be underestimated. Additionaly, the techniques employed during chromosome count may be expensive and timeconsuming. In this regard, DNA fingerprinting appears as a much better option for hybrid recognition due to their high availability in the genome, their neutrality and the ease with which large amounts of data may be obtained.

It is undeniable that DNA fingerprinting techniques are the best option for hybrid recognition. When correctly employed, they are able to detect later generation hybrids with high reliability. However, while DNA-based markers are the prime marker when studying whether or not hybridization occurs between a species pair and its frequency, other important questions arise about the fate that hybrids will have under natural conditions: How can we recognize these hybrids under field conditions? Will they exhibit a higher resistance/tolerance to pathogens? Will they possibly exhibit a higher fitness than pure parental individuals? These questions may be answered using a cytological approach as well as molecular and secondary metabolite markers. Whether hybridization is carried out under natural or greenhouse conditions, these questions may be very important issues. The relevance of these questions is exacerbated when considering the global changes occurring on earth; global warming, deforestation, and the introduction of exotic species favor the sympatry between species that are previously allopatric. As hybridization introduces much more genetic diversity than mutation alone, it may confer hybrids with advantageous characteristics that may alter significantly the ecosystems where they grow.

So, while DNA fingerprinting techniques are really useful to unveil the existence and frequency of natural hybridization, the use of other markers may give insights of the ecological performance of hybrids.

\section{Competing interests}

The authors declare that they have no competing interests.

\section{Authors' contributions}

Both authors participated in the review topic design, in the data analyses and in the manuscript writing. Also, both authors read and approved the final version of the manuscript.

\section{Acknowledgements}

This research was supported by scholarship from CONACYT-SEP Mexico to A. L.C. We also thank the Posgrado en Ciencias Biológicas (UNAM).

\section{Author details}

'Departamento de Sistemática y Evolución, Centro de Investigación en Biodiversidad y Conservación, Universidad Autónoma del Estado de Morelos, Av. Universidad 1001, Col. Chamilpa, Cuernavaca, Morelos CP 62209, México. ${ }^{2}$ Posgrado en Ciencias Biológicas, Universidad Nacional Autónoma de México, Apartado Postal 70-181, 04510 Delegación Coyoacán, México.

Received: 24 April 2014 Accepted: 2 July 2014

Published online: 01 August 2014

\section{References}

Abbott RJ, Hegarty MJ, Hiscock SJ, Brennan AC (2010) Homoploid hybrid speciation in action. Taxon 59:1375-1386

Adams KL, Wendel JF (2005) Polyploidy and genome evolution in plants. Curr Opin Plant Biol 8:135-141

Alston RE, Turner BL (1962) New techniques in analysis of complex natural hybridization. P Natl Acad Sci 48:130-137

Anderson E (1949) Introgressive hybridization. John Wiley, New York

Anderson EC, Thompson EA (2002) A model-based method for identifying species hybrids using multilocus genetic data. Genetics 160:1217-1229

Arnold ML (1997) Natural hybridization and evolution. Oxford University Press, New York

Arnold ML (2006) Evolution through genetic exchange. Oxford University Press, New York

Barrier M, Baldwin BG, Robichaux RH, Purugganan MD (1999) Interspecific hybrid ancestry of a plant adaptive radiation: allopolyploidy of the Hawaiian Silversword alliance (Asteraceae) inferred from floral homeotic gene duplications. Mol Biol Evol 16:1105-1113

Bell MA, Travis MP (2005) Hybridization, transgressive segregation, genetic covariation, and adaptive radiation. Trends Ecol Evol 20:358-361

Blair AC, Hufbauer RA (2010) Hybridization and invasion: one of North America's most devastating invasive plants shows evidence for a history of interspecific hybridization. Evol Appl 3:40-51

Boecklen WJ, Howard DJ (1997) Genetic analysis of hybrid zones: number of markers and power of resolution. Ecology 78:2611-2616

Bradley R (1717) New Improvements of planting and gardening both philosophical and practical, explaining the motion of sap and generation of plants. W. Mears, London

Campbell DR, Alarcón R, Wu CA (2003) Reproductive isolation and hybrid pollen disadvantage in Ipomopsis. J Evolution Biol 16:536-540

Caraway V, Carr GD, Morden CW (2001) Assessment of hybridization and introgression in lava-colonizing Hawaiian Dubautia (Asteraceae: Madiinae) using RAPD markers. Am J Bot 88:1688-1694

Chen ZJ (2013) Genomic and epigenetic insights into the molecular bases of heterosis. Nat Rev Genet 14:471-482

Cheng D, Vrieling K, Klinkhammer PGL (2011) The effect of hybridization on secondary metabolites and herbivore resistance: Implications for the evolution of chemical diversity in plants. Phytochem Rev 10:107-117

Chew FS, Courtney SP (1991) Plant apparency and evolutionary escape from insect herbivory. Am Nat 138:729-750

Chybicki IJ, Burczyk J (2009) Simultaneous estimation of null alleles and inbreeding coefficients. J Hered 100:106-113

Comai L (2005) The advantages and disadvantages of being polyploid. Nat Rev Genet 6:836-846

Comes HP, Abbott RJ (1999) Population genetic structure and gene flow across arid versus mesic environments: a comparative study of two parapatric Senecio species from the near east. Evolution 53:36-54

Corander J, Marttinen P (2006) Bayesian identification of admixture events using multilocus molecular markers. Mol Ecol 15:2833-2843

Correns CE (1900) G. Mendel's regel über das verhalten der nachkommenschaft der rassenbastarde. Berichte der Deutschen Botanischen Gesellschaft 18:158-167

Crawford DJ, Giannasi DE (1982) Plant chemosystematics. BioScience 32:114-124

Darwin CR (1859) The Origin of Species. Avenel, New York

De Vries H (1900) Das spaltungsgesetz der bastarde. Berichte der Deutschen Botanischen Gelellschaft 18:83-90

Dobzhansky T (1940) Speciation as a stage in evolutionary divergence. Am Nat 753:312-321

Dobzhansky T (1970) Genetics of the evolutionary process. Columbia University Press, New York

Driebe EM, Whitham TG (2000) Cottonwood hybridization affects tannin and nitrogen content of leaf litter and alters decomposition. Oecologia 123:99-107

Ellstrand NC, Schierenbeck KA (2000) Hybridization as a stimulus for the evolution of invasiveness in plants? P Natl Acad Sci 97:7043-7050

Firn RD, Jones CG (2003) Natural products-a simple model to explain chemical diversity. Nat Prod Rep 20:382-391

Gärtner CF (1827) Notice sur des experiences concernant la fecondation de quelques vegetaux. Annales des Sciences Naturelles 10:113-148

Godron DA (1863) Recherches experimentales sur l'hybridité dans le regne végétale. L'Académie de Stanislas, Mémoires de

Grant V (1975) Genetics of flowering plants. Columbia University Press, New York

Grant V (1981) Plant Speciation. Columbia University Press, New York 
Gross BL, Rieseberg LH (2005) The ecological genetics of homoploid hybrid speciation. J Hered 96:241-252

Gross BL, Schwarzbach AE, Rieseberg LH (2003) Origin(s) of the diploid hybrid species Helianthus deserticola (Asteraceae). Am J Bot 90:1708-1719

Haartman J (1764) Plantae hybridae. Amoenitates Acdemicae 3:28-52

Hadrys H, Balick M, Schierwater B (1992) Applications of random amplified polymorphic DNA (RAPD) in molecular ecology. Mol Ecol 1:55-63

Hallgren P, Ikonen A, Hältén J, Roininen H (2003) Inheritance patterns of phenolics in F1, F2, and back-cross hybrids of willows: Implications for herbivore responses to hybrid plants. J Chem Ecol 29:1143-1158

Hardig TM, Brunsfeld SJ, Fritz RS, Morgan M, Orians CM (2000) Morphological and molecular evidence for hybridization and introgression in a willow (Salix) hybrid zone. Mol Ecol 9:9-24

Harlan JR, deWet JMJ (1975) On O. Wingë and a prayer: the origins of polyploidy. Bot Rev 41:361-390

Harrison RG (1990) Hybrid zones: windows on evolutionary process. Oxford Surv Evolution Biol 7:69-128

Hebert W (1847) On hybridisation amongst vegetables. Journal of the Horticultural Society 2:1-28

Hohenlohe PA, Amish SJ, Catchen JM, Allendorf FW, Luikart G (2011) Next-generation RAD sequencing identifies thousands of SNPs for assessing hybridization between rainbow and westslope cutthroat trout. Mol Ecol Resour 11:117-122

Howard DJ, Preszler RW, Williams J, Fenchel S, Boecklen WJ (1997) How discrete are oak species? Insights from a hybrid zone between Quercus grisea and Q gambelli Evolution 5:747-755

Jeffreys AJ, Wilson V, Thein SL (1985) Individual-specific 'fingerprints' of human DNA. Nature 316:76-79

Judd WS, Campbell CS, Kellogg EA, Stevens PF, Donoghue MJ (2002) Plant Systematics, a phylogenetic approach. Sinauer Associates, Massachusetts

Kalia RK, Rai MK, Kalia S, Singh R, Dhawan AK (2011) Microsatellite markers: an overview of the recent progress in plants. Euphytica 177:309-334

Kirk H, Mácel M, Klinkhamer PGL, Vrieling K (2004) Natural hybridization between Senecio jacobaea and Senecio aquaticus: molecular and chemical evidence. Mol Ecol 13:2267-2274

Kirk H, Cheng D, Choi YH, Vrieling K, Klinkhamer PGL (2012) Transgressive segregation of primary and secondary metabolites in F2 hybrids between Jacobaea aquatica and J. vulgaris. Metabolomics 8:211-219

Knight TA (1799) An account of some experiments of the fecundation of vegetables. Philos T Roy Soc B 1:195-204

Kölreuter JG (1761) Vorläufige Nachricht von einigen das Geschlecht der Pflanzen betreffenden Versuchen und Beobachtungen, nebst Fortsetzungen. In der Gleditschischen Handlung, Leipzig

Koontz JA, Soltis PS, Soltis DE (2004) Using phylogeny reconstruction to test hypothesis of hybrid origin in Delphinium section Diedropetala (Ranunculaceae). Syst Bot 29:345-357

La Duke JC (1982) Flavonoid chemistry and systematics of Tithonia (Compositae). Am J Bot 69:784-792

Lamont BB, He T, Enright NJ, Krauss SL, Miller BP (2003) Anthropogenic disturbance promotes hybridization between Banksia species by altering their biology. J Evolution Biol 16:551-557

Lawton-Rauh A, Robichaux RH, Purugganan MD (2003) Patterns of nucleotide variation in homoeologous regulatory genes in the allotetraploid Hawaiian Silversword alliance (Asteraceae). Mol Ecol 12:1301-1313

Levin DA (1983) Polyploidy and novelty in flowering plants. Am Nat 122:1-25

Levin DA, Francisco-Ortega J (1996) Hybridization and the extinction of rare plant species. Conserv Biol 10:10-16

Lexer C, Welch ME, Durphy L, Rieseberg LH (2003) Natural selection for salt tolerance quantitative trait loci (QTLs) in wild sunflower hybrids: Implications for the origin of Helianthus paradoxus, a diploid hybrid species. Mol Ecol 12:1225-1235

Lihová J, Kucera J, Perný M, Marhold K (2007) Hybridization between two polyploid cardamine (Brassicaceae) species in north-western Spain: discordance between morphological and genetic variation patterns. Ann Bot 99:1083-1096

Mallet J (2005) Hybridization as an invasion of the genome. Trends Ecol Evol 20:229-237

Mallet J (2007) Hybrid speciation. Nature 446:279-283

Marshall JL, Arnold ML, Howard DJ (2002) Reinforcement: the road not taken. Trends Ecol Evol 17:558-563

Mayr $E$ (1942) Systematics and the origin of species, from the viewpoint of a zoologist. Harvard University Press, Cambridge
Mayr E (1963) Animal species and evolution. Harvard University Press, Cambridge

McDade L (1990) Hybrids and phylogenetic systematics. I Patterns of character expression in hybrids and their implications for cladistic analysis Evolution 44:1685-1700

McDade L (1992) Hybrids and phylogenetic systematics. II The impact of hybrids on cladistic analysis Evolution 46:1329-1346

Metzker ML (2010) Sequencing technologies - the next generation. Nat Rev Genet 11:31-46

Meyerson LA, Viola DV, Brown RN (2010) Hybridization of invasive Phragmites australis with a native subspecies in North America. Biol Invasions 12:103-111

Mooney HA, Cleland E (2001) The evolutionary impact of invasive species. P Natl Acad Sci 98:5446-5451

Müntzing A (1930) Outlines to a genetic monograph of the genus Galeopsis. Hereditas 13:185-341

Nägeli C (1865) Über den Einfluss der ausseren Verhältnisse auf die Varietatenbildung im Pflanzenreiche. Botanische Mittheilungen 2:103-58

Naudin C (1863) Nouvelles recherches sur l'hybridite dans les vegetaux. Annales des Sciences Naturelles, Botanique 19:180-203

Newaskar GS, Chimote VP, Mehetre SS, Jadhav AS (2013) Interspecific hybridization in Gossypium L:: characterization of progenies with different ploidy-confirmed multigenomic backgrounds. Plant Breeding 132:211-216

Oberprieler C, Barth A, Schwarz S, Heilmann J (2010) Morphological and phytochemical variation, genetic structure and phenology in an introgressive hybrid swarm of Senecio hercynicus and S. ovatus (Compositae, Senecioneae). Plant Syst Evol 286:152-166

Oberprieler C, Hartl S, Schauer K, Meister J, Heilmann J (2011) Morphological, phytochemical and genetic variation in mixed stands and a hybrid swarm of Senecio germanicus and S. ovatus (Compositae, Senecioneae). Plant Syst Evol 293:177-191

Orians CM (2000) The effects of hybridization in plants on secondary chemistry: Implications for the ecology and evolution of plant-herbivore interactions. American Journal of Botany 87:1749-1756

Ownbey M (1950) Natural hybridization and amphidiploidy in the genus Tragopogon. Am J Bot 37:487-499

Paun O, Forest F, Fay MF, Chase MW (2009) Hybrid speciation in angiosperms: parental divergence drives ploidy. New Phytol 182:507-518

Peffley EB, Mangum PD (1990) Introgression of Allium fistulosum L. into Allium cepa L.: cytogenetic evidende. Theor Appl Genet 79:113-118

Pelser PB, Kennedy AH, Tepe EJ, Shidler JB, Nordenstam B, Kadereit JW, Watson LE (2010) Patterns and causes of incongruence between plastid and nuclear Senecioneae (Asteraceae) phylogenies. Am J Bot 97:856-873

Petit RJ, Bodénès C, Ducousso A, Roussel G, Kramer A (2004) Hybridization as a mechanism of invasion in oaks. New Phytol 161:151-164

Piry S, Alapetite A, Cornuet JM, Paetkau D, Baudouin L, Estoup A (2004) GENECLASS2: A software for genetic assignment and first-generation migrant detection. J Hered 95:536-539

Prince VE, Pickett FB (2002) Splitting pairs: the diverging fates of duplicated genes. Nat Rev Genet 3:827-837

Pritchard JK, Stephens M, Donelly P (2000) Inference of population structure using multilocus genotype data. Genetics 155:945-959

Ramsey J, Schemske DW (1998) Pathways, mechanisms, and rates of polyloidy formation in flowering plants. Annu Rev Ecol Syst 29:467-501

Rhymer JM, Simberloff D (1996) Extinction by hybridization and introgression. Ann Rev Ecol Syst 27:83-109

Rieseberg LH (1991) Homoploid reticulate evolution in Helianthus: evidence from ribosomal genes. Am J Bot 78:1218-1237

Rieseberg LH (1995) The role of hybridization in evolution: Old wine in new skins. Am J Bot 82:944-953

Rieseberg LH (1997) Hybrid origins of plant species. Ann Rev Ecol Syst 28:359-289

Rieseberg LH, Carney SE (1998) Plant hybridization. New Phytol 140:599-624

Rieseberg LH, Ellstrand NC (1993) What can molecular and morphological markers tell us about plant hybridization? Crit Rev Plant Sci 12:213-241

Rieseberg LH, Gerber D (1995) Hybridization in the Catalina Island mountain mahogany (Cercocarpus traskiae): RAPD's evidence. Conserv Biol 9:199-203

Rieseberg LH, Soltis DE (1991) Phylogenetic consequences of cytoplasmic gene flow in plants. Evol Trend Plant 5:65-84

Rieseberg LH, Wendel JF (1993) Introgression and its consequences in plants. In: Harrison R (ed) Hybrid zones and the evolutionary process. Oxford University Press, Oxford

Rieseberg LH, Archer MA, Wayne RK (1999) Transgressive segregation, adaptation, and speciation. Heredity 83:363-372 
Rieseberg LH, Widmer A, Arntz AM, Burke JM (2003) The genetic architecture necessary for transgressive segregation is common in both natural and domesticated populations. Philos T Roy Soc B 358:1141-1147

Rieseberg LH, Kim S, Randell RA, Whitney KD, Gross BL, Lexer C, Clay K (2007) Hybridization and the colonization of novel habitats by annual sunflowers. Genetica 129:149-165

Roberts HF (1929) Plant hybridization before Mendel. Princeton, New Jersey

Roose ML, Gottlieb LD (1976) Genetic and biochemical consequences of polyploidy in Tragopogon. Evolution 30:818-830

Saad L, Tiébré M, Hardy OJ, Mahy G, Vanderhoeven S (2011) Patterns of hybridization and hybrid survival in the invasive alien Fallopia complex (Polygonaceae). Plant Ecol Evol 144:12-18

Sapir Y, Moody ML, Brouillette LC, Donovan LA, Rieseberg LH (2007) Patterns of genetic diversity and candidate genes for ecological divergence in homoploid hybrid sunflower, Helianthus anomalus. Mol Ecol 16:5017-5029

Schierenbeck KA, Ellstrand NC (2009) Hybridization and the evolution of invasiveness in plants and other organisms. Biol Invasions 11:1093-1105

Schwarzbach AE, Donovan LA, Rieseberg LH (2001) Transgressive character expression in a hybrid sunflower species Am J Bot 88:270-277

Schwenk K, Brede N, Streit B (2008) Introduction. Extent, processes and evolutionary impact of interspecific hybridization in animals. Philos T Roy Soc B 363:2805-2811

Soltis DE, Soltis PS (1993) Molecular data and the dynamic nature of polyploidy. Crit Rev Plant Sci 12:243-275

Soltis DE, Mavrodiev EV, Doyle JJ, Rauscher J, Soltis PS (2008) ITS and ETS sequence data and phylogeny reconstruction in allopolyploids and hybrids. Syst Bot 33:7-20

Soltis DE, Buggs RJA, Doyle JJ, Soltis PS (2010) What we still don't know about polyploidy. Taxon 59:1387-1403

Sprengel CK (1793) Das entdeckte Geheimnis der Natur im Bau und in der Befruchtung der Blumen. Vieweg d. Ä, Berlin

Stebbins GL (1950) Variation and evolution in plants. Columbia University Press, New York

Stebbins GL (1959) The role of hybridization in evolution. P Am Philos Soc 103:231-251

Stelkens R, Seehausen O (2009) Genetic distance between species predicts novel trait expression in their hybrids. Evolution 63:884-897

Stift M, Berenos C, Kuperus P, van Tienderen PH (2008) Segregation models for disomic, tetrasomic and intermediate inheritance in tetraploids: A general procedure applied to Rorippa (Yellow cress) microsatellite data. Genetics 179:2113-2123

Strong DR, Ayres DR (2013) Ecological and evolutionary misadventures of Spartina. Annu Rev Ecol Evol Syst 44:389-410

Suárez-Santiago VN, Díaz de la Guardia C, Soltis DE, Soltis PS, Blanca G (2011) Tragopogon lainzii, a new species of Tragopogon (Asteraceae) segregated form T. dubius: Evidence from morphological and molecular data. Syst Bot $36: 470-480$

Sutton WS (1902) On the morphology of the chromosome group in Brachystola magna. Biol Bull 4:24-39

Sutton WS (1903) The chromosomes in heredity. Biol Bull 4:231-251

Tabernaemontanus (1731) Kräuterbuch. Johan Ludwig König, Basel

Templeton AR (1989) The meaning of species and speciation: a genetic perspective. In: Otte D, Endler JA (eds) Speciation and its Consequences. Sinauer Associates, Sunderland

Tovar-Sánchez E, Oyama K (2006) Community structure of canopy arthropods associated to Quercus crassifolia × Quercus crassipes complex. Oikos 112:370-381

Tovar-Sánchez E, Rodríguez-Carmona F, Aguilar-Mendiola V, Mussali-Galante P, López-Caamal A, Valencia-Cuevas L (2012) Molecular evidence of hybridization in two native invasive species: Tithonia tubaeformis and T. rotundifolia (Asteraceae) in Mexico. Plant Syst Evol 298:1947-1959

Travis SE, Marburger JE, Windels S, Kubátova B (2010) Hybridization dynamics of invasive cattail (Typhaceae) stands in the western great lakes region of North America: A molecular analysis. J Ecol 98:7-16

Tschermak E (1900) Ueber künstliche kreuzung bei Pisum sativum. Berichteder Deutschen Botanischen Gesellschaft 18:232-249

Tucker RT, Behm JE (2011) Hybridization, species collapse, and species reemergence after disturbance to premating mechanisms of reproductive isolation. Evolution 65:2591-2605

Twyford AD, Ennos RA (2012) Next-generation hybridization and introgression. Heredity 108:179-189
Vähä JP, Primmer CR (2006) Efficiency of model-based Bayesian methods for detecting hybrid individuals under different hybridization scenarios and with different numbers of loci. Mol Ecol 15:63-72

van Raamsdonk LWD, Vrielink-van Glinkel M, Kik C (2000) Phylogeny reconstruction and hybrid analysis in Allium subgenus Rhizirideum. Theor Appl Genet 100:1000-1009

Vilà M, Weber E, D'Antonio CM (2000) Conservation implications of invasion by plant hybridization. Biol Invasions 2:207-217

Voigt PW, Tischler CR (1994) Leaf characteristic variation in hybrid lovegrass populations. Crop Sci 34:679-684

Vos P, Hogers R, Bleeker M, Reijans M, Van de Lee T, Hornes M, Friters A, Pot J, Paleman J, Kuiper M, Zabeau M (1995) AFLP: a new technique for DNA fingerprinting. Nucl Acids Res 23:4407-4414

Wagner WH (1969) The role and taxonomic treatment of hybrids. BioScience 19:785-789

Whitney KD, Ahern JR, Campbell LG, Albert LP, King MS (2010) Patterns of hybridization in plants. Perspec Plant Ecol 12:175-182

Williams JGK, Kubelik AR, Livak KJ, Rafalski JA, Tingey SV (1990) DNA polymorphisms amplified by arbitrary primers are useful as genetic markers. Nucl Acids Res 18:6531-6535

Wilson P (1992) On inferring hybridity from morphological intermediacy. Taxon 41:11-23

Winge Ö (1917) The chromosomes, their number and general importance. Compt Rend Trav Carlsberg Lab 13:131-275

Wissemann V (2007) Plant evolution by means of hybridization. Syst Biodivers 5:243-253

Zalapa JE, Brunet J, Guries RP (2010) The extent of hybridization and its impact on the genetic diversity and population structure of an invasive tree, Ulmus pumila (Ulmaceae). Evol Appl 3:157-168

Zirkle C (1934) More records of plant hybridization before Köelreuter. J Hered 25:3-18

Zirkle C (1935) The beginnings of plant hybridization. Morris Arboretum Monographs 1. University of Pennsylvania Press, Philadelphia

Zobel B (1951) Oleoresin composition as a determinant of pine hybridity. Bot Gaz 113:221-227

doi:10.1186/s40693-014-0016-0

Cite this article as: López-Caamal and Tovar-Sánchez: Genetic, morphological, and chemical patterns of plant hybridization. Revista Chilena de Historia Natural 2014 87:16.

\section{Submit your manuscript to a SpringerOpen ${ }^{\circ}$ journal and benefit from:}

- Convenient online submission

- Rigorous peer review

- Immediate publication on acceptance

- Open access: articles freely available online

- High visibility within the field

- Retaining the copyright to your article

Submit your next manuscript at $>$ springeropen.com 